\title{
PERENCANAAN PERKUATAN LERENG PADA SUNGAI WAY BATANGHARI MENGGUNAKAN METODE IRISAN (METHOD OF SLICE) DENGAN CARA FELLENIUS (STUDI KASUS LERENG PADA DAERAH ALIRAN SUNGAI WAY BATANGHARI, BELAKANG KAMPUS 1 UNIVERSITAS MUHAMMADIYAH METRO)
}

\author{
Yusuf Amran ${ }^{1}$, Abdi Saputra ${ }^{2}$, Agus Surandono ${ }^{3}$ \\ Prodi Teknik Sipil Universitas Muhammadiyah Metro ${ }^{1,2,3}$ \\ E-mail : yusufamran307@gmail.com ${ }^{1}$, abdisaputra90@gmail.com², \\ agussurandono@yahoo.co.id ${ }^{3}$
}

\begin{abstract}
ABSTRAK
Saat ini berbagai sektor kegiatan pembangunan mengalami pertumbuhan yang pesat. Dalam perkembangannya, perencanaan wilayah atau penetapan pusat pengembangan kawasan permukiman justru berada di kawasan rawan yaitu kawasan sungai. Sungai menyediakan banyak sumber kehidupan. Kegiatan pengamanan tersebut meliputi pengamanan tanggul sungai.

Dalam studi kasus ini, upaya pencegahan dan pengamanan tanggul/lereng sungai dapat dilakukan dengan cara memperkuat dan memperbaiki lereng yang harus digunakan dan dianalisis terlebih dahulu sebelum dilakukan perencanaan teknis. Perencanaan/analisa lereng sungai diharapkan dapat meminimalisir beberapa hal yang dapat mengganggu kestabilan gaya geser, kestabilan gaya gulir, daya dukung tanah yang dapat mengakibatkan longsoran pada lereng dengan menggunakan beberapa metode seperti slice of method di lereng sungai way batanghari yang tepatnya berada di belakang Kampus 1 Universitas Muhammadiyah Metro.

Berdasarkan uraian kondisi geoteknik dan hidro seperti diuraikan di atas, maka perlu dilakukan suatu analisis yang diperlukan sebagai dasar perencanaan lereng serta perencanaan struktur dinding penahan tanah di masa yang akan datang, termasuk analisis hidrologi, kemiringan lereng dan analisis stabilitas. Dalam analisis hidrologi digunakan metode rasional untuk menentukan perhitungan debet rencana. Perhitungan stabilitas tekanan tanah dihitung menggunakan teori Rankine dan Coulomb dan perhitungan stabilitas terhadap runtuhnya daya dukung tanah dihitung berdasarkan persamaan hansen dan vesik berdasarkan data karakteristik teknis.

Dari analisa kestabilan lereng dengan metode irisan dengan cara fellenius, diperoleh faktor keamanan (FK) terbesar yaitu 3,789>1,5 dalam hal ini lereng dalam keadaan stabil atau aman dari bahaya longsor. Berdasarkan hasil perhitungan debit rembesan diperoleh debit rembesan pada badan lereng sebesar $=5,34 \times 10-5 \mathrm{~m}^{3} / \mathrm{det}$, debit air yang terjadi pada badan lereng pada saat penggenangan dapat mempengaruhi penurunan kestabilan lereng, dimana Penghancuran akan menimbulkan gejala piping (proses menerangi butir-butir tanah halus yang menyebabkan air mengalir di badan lereng).
\end{abstract}

Keyword : Stabilitas Lereng, Sungai Way Batanghari, Kota Metro. 


\section{PENDAHULUAN}

Stabilitas suatu lereng dan keadaan dinding penahan tanah yang representatif adalah hal yang tidak dapat di tawartawar lagi demi keselamatan masyarakat yang bermukim dipinggir-pinggir daerah yang mengandalkan lereng yang stabil dan dinding penahan tanah sebagai sebagai penopang pondasi bangunannya. Karena banyak bangunan yang berada di daerah aliran sungai, maka kekuatan pondasi pada bangunan yang berada di pinggiran daerah sungai ini harus didukung oleh lereng yang kuat dan stabil yang dapat menahan tekanan tanah beban pondasi, sehingga lereng dan dinding penahan tanah tersebut tidak mengalami keruntuhan/longsor. Adanya morfologi sungai dengan pengertian sungai terbentuk sesuai dengan kondisi geografi, ekologi, dan hidrologi daerah setempat akan mempengaruhi kesimbangan dinamika sungai. Disamping itu, aktivitas manusia (antropogenik activities) di sungai merupakan faktor yang sangat penting pada perubahan morfologi sungai.

Pada studi kasus ini, peneliti akan membahas analisis/perencanaan stabilitas lereng sebagai dasar perkuatan lereng tanah pada daerah aliran sungai Way Batanghari yang tepatnya terletak di belakang Kampus 1 Universitas Muhammadiyah Metro. Daerah ini merupakan daerah yang terletak di kawasan tempat pendidikan, di manana disekililing rusunawa ini berdiri berbagai jenis bangunan. Bangunan tersebut berupa gedung perkulihan (kampus), sekolah, dan kantor-kantor pemerintahan. Kampus perguruan tinggi yang berdiri di sekitar lokasi ini diantaranya, Kampus 1 Universitas Muhammadiyah Metro dan IAIN Jurai Siwo Kota Metro. Terdapat pula sekolah, yaitu MAN 1 Metro, SMP N 2 Metro, dan lainnya. Selain itu juga masih banyak gedung pemerintahan lainnya, seperti Kantor Dinas Pendidikan Kota Metro, ada juga tempat pelayanan kesehatan yaitu puskesmas Iringmulyo. Otomatis daerah ini sangat ramai dan padat dengan berbagai macam kegiatan yang berlangsung di kawasan ini, sehingga lambat laun pasti akan mempengaruhi tata guna lahan pada daerah tersebut. Apalagi rusunawa yang belum lama berdiri ini terletak di dekat bantaran sungai, dimana akan dipastikan mempengaruhi kondisi sungai yang letaknya di belakang rusunawa tesebut.

Lokasi titik ini membutuhkan adanya proteksi tanah, dengan adanya perubahan tata guna lahan tersebut guna untuk mencegah terjadinya pergerakan tanah yang mengakibatkan perubahan kondisi tanah setempat dan gerusan sungai. Keadaan pada titik lokasi ini, sudah terdapat gerusan yang mengikis lereng sungai karena tidak terawatnya tumbuh-tumbuhan yang tumbuh di sekitar lokasi penelitian ini. Di lokasi ini belum ada usaha perkuatan tanah pada lereng sungai, sehingga lambat laun pada lokasi ini perlu dibangunnya konstruksi perkuatan lereng sungai atau dinding penahan tanah sungai. Dengan adanya perkuatan ini diharapkan mampu mengatasi gerusan sungai dan aman dari bahaya penurunan tanah, pengikisan atau longsoran. Struktur tanah ini diharapkan juga dapat meningkatkan kapasitas tanggul/lereng sunai serta mengamankan tanah sungai agar aman terhadap debit arus sungai yang mengalir.

\section{TINJAUAN PUSTAKA}

\section{Pengertian Sungai}

Sungai atau saluran terbuka menurut Triatmodjo (2003:103) adalah saluran dimana air mengalir dengan muka air bebas. Pada saluran terbuka, misalnya sungai (saluran alam), variabel aliran sangat tidak teratur terhadap ruang dan waktu. Variabel tersebut adalah tampang lintang saluran, kekasaran, kemiringan dasar, belokan, debit aliran dan sebagainya. 
Sungai adalah alur atau wadah air alami dan/atau bauatan berupa jaringan pengaliran air beserta air di dalamnya, mulai dari hulu sampai muara, dengan dibatasi kanan dan kiri oleh garis sempadan (Peraturan Mentri Pekerjaan Umum dan Perumahan Rakyat Republik Indonesia Nomor. 28/PRT/M/2015, Tentang Penetapan Garis Sepandan Sungai dan Garis Sepandan Danau).

\section{Morfologi Sungai}

Morfologi sungai adalah ilmu yang mempelajari tentang bentuk dan ukuran (geometri) jenis, sifat dan perilaku sungai dengan segala aspek dan perubahannya dalam dimensi ruang dan waktu. Dengan demikian, morfologi sungai tersebut menggambarkan keterpaduan antara karakteristik abiotik (fisik-hidrologisedimen, dll) dan karakteristik biotik (biologi atau ekologi-flora fauna) daerah yang dilaluinya, faktor yang berpengaruh terhadap morfologi sungai tidak hanya faktor abiotik dan biotik, namun juga campur tangan manusia dalam aktifitasnya mengadakan pembangunanpembangunan di wilayah sungai (sosial antropogenik). Pengaruh campur tangan ini dapat mengakibatkan perubahan morfologi sungai yang jauh lebih cepat dari pada pengaruh alamiah biotik dan abiotik saja.

\section{Banjir}

Banjir adalah suatu kondisi dimana tidak tertampungnya air dalam saluran pembuang (kali) atau terhambatnya aliran air di dalam saluran pembuang. (Suripin, "Sistem Drainase Perkotaan yang Berkelanjutan”). Banjir merupakan peristiwa alam yang dapat menimbulkan kerugian harta benda penduduk serta dapat pula menimbulkan korban jiwa. Dikatakan banjir apabila terjadi luapan atau jebolan dan air banjir, disebabkan oleh kurangnya kapasitas penampang saluran pembuang. Banjir di bagian hulu biasanya arus banjirnya deras, daya gerusnya besar, tetapi durasinya pendek.
Sedangkan di bagian hilir arusnya tidak deras (karena landai), tetapi durasi banjirnya panjang.

Beberapa karakteristik yang berkaitan dengan banjir, diantaranya:

Banjir dapat datang secara tiba-tiba dengan intensitas besar namun dapat langsung mengalir. Banjir dating secara perlahan namun dapat menjadi genangan yang lama (berhari-hari atau bahkan berminggu-minggu) di daerah depresi. Banjir datang secara perlahan namun intensitas hujannya sedikit. Pola banjirnya musiman.

Akibat yang ditimbulkan adalah terjadinya genangan, erosi dan sedimentasi. Sedangkan akibat lainnya terisolasinya daerah pemukiman dan diperlukan evakuasi penduduk.

\section{Analisis Stabilitas Lereng}

Pada permukaan tanah yang miring, komponen gravitasi cenderung untuk menggerakan tanah ke bawah. Jika komponen gravitasi sedemikian besar sehingga perlawanan geseran yang dapat dikerahkan oleh tanah pada bidang longsornya terlampaui, maka akan terjadi kelongsoran lereng. Analisis stablitas lereng mempunyai banyak faktor yang mempengaruhi hasil hitungan. Faktor tersebut misalnya, kondisi tanah berlapislapis, kuat geser tanah anisotropis, aliran rembesan dalam tanah dan lain-lain. Secara umum longsor suatu lereng dikarenakan bertambahnya tegangan geser (shear stress) dan berkurangnya kuat geser tanah (shear strength). Bertambahnya tegangan geser dapat disebabkan antara lain bagian penahan lereng seperti dinding penahan tanah, perubahan muka air tanah yang begitu cepat, dan beban akibat gempa bumi.

Analisis stabilitas tanah pada permukaan yang miring ini disebut analisis stabilitas lereng. Analisis ini sering sering juga digunakan pada perencanaan perencanaan kontruksi sipil seperti : jalan, kereta api, bandara, tanggul, dan lain-lain. Maksud analisis stabilitas 
lereng adalah untuk menentukan faktor aman dari bidang longsor. Faktor aman didefinisikan sebagai nilai banding anatar gaya yang menahan dan gaya yang menggerakan.

$\mathrm{Fk}=\frac{\tau}{\tau_{\mathrm{d}}}$

dimana :

$\tau=$ Tegangan Geser Maksimum Yang Dapat Dikerahkan Oleh Tanah

$\tau_{\mathrm{d}}=$ Tegangan Geser Yang Terjadi Akibat Gaya Berat Tanah Yang Akan Longsor

FK $=$ Faktor Keamanan

Untuk maksud memberikan faktor aman terhadap masing-masing komponen kuat geser, faktor aman dapat dinyatakan oleh: $\mathrm{F}_{\mathrm{C}}=\frac{\mathrm{c}}{\mathrm{c}_{\mathrm{d}}}$

$F \varphi=\frac{\operatorname{tg} \varphi}{\operatorname{tg} \varphi_{d}}$

Dengan ;

$F_{c}=$ faktor aman pada komponen kohesi dan $F \varphi=$ faktor keamanan pada komponen gesekan. Secara teoritis tingkat nilai faktor keamanan.

Tabel 1. Tingkat Nilai FK

\begin{tabular}{|c|c|}
\hline FK & Keterangan \\
\hline$>1,5$ & Stabil \\
\hline$=1,5$ & Kritis \\
\hline$<1,5$ & Labil \\
\hline
\end{tabular}

(ASTM)

\section{Analisis Stabilitas Lereng Berbentuk Lingkaran}

Untuk lereng tanah homogen, kebanyakan peristiwa longsoran tanah terjadi dengan bentuk bidang longsor yang berupa lengkungan. Lengkung bidang longsor dapat berbentuk bidang lingkaran (silinder), spiral logaritma ataupun kombinasi dari keduanya. Bentuk anggapan bidaang longsor berupa lingkaran dimaksudkan untuk mempermudah hitungan analisis stabilitas secara matematik, keakuratan hasil hitungan analisis stabilitas lereng, sangat bergantung pada sifat tanah dan lokasi bidang longsor kritisnya.

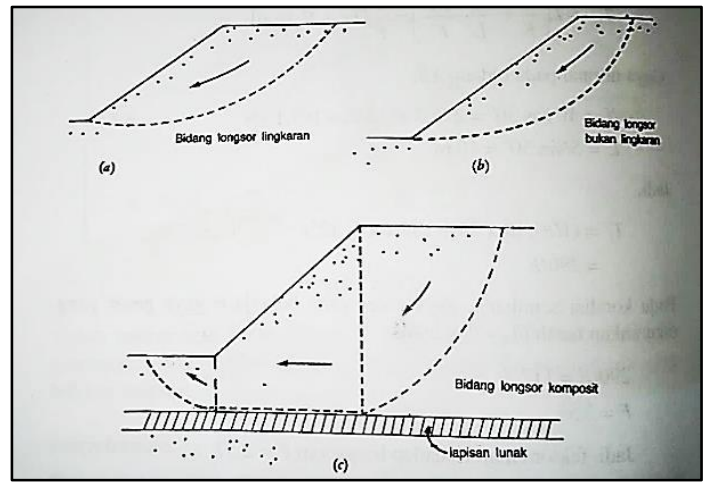

Gambar 1. Bentuk - Bentuk Bidang Lonsor Pada Lereng

\section{Analisis Stabilitas Lereng Tanah Kohesif}

$\mathrm{FK}=\frac{\text { Jumlah momen yang menahan }}{\text { Jumlah momen yang menggerakan }}$

$\mathrm{FK}=\frac{\sum \mathrm{M}_{\mathrm{r}}}{\sum \mathrm{M}_{\mathrm{d}}}=\frac{\mathrm{RcL}_{\mathrm{AC}}}{\mathrm{Wy}}$

dimana :

$\mathrm{FK}=$ Faktor Keamanan

$\mathrm{W}=$ Berat Tanah Yang Akan Lonsor

$\mathrm{L}_{\mathrm{AC}}=$ Panjang Lengkungan $(\mathrm{m})$

$\mathrm{c} \quad=$ Kohesi $\left(\mathrm{kN} / \mathrm{m}^{2}\right)$

$\mathrm{R}=$ Jari-Jari Lingkaran Bidang

Longsor Yang Ditinjau (m)

$\mathrm{y}=$ Jarak Pusat Berat W Terhadap o $(\mathrm{m})$

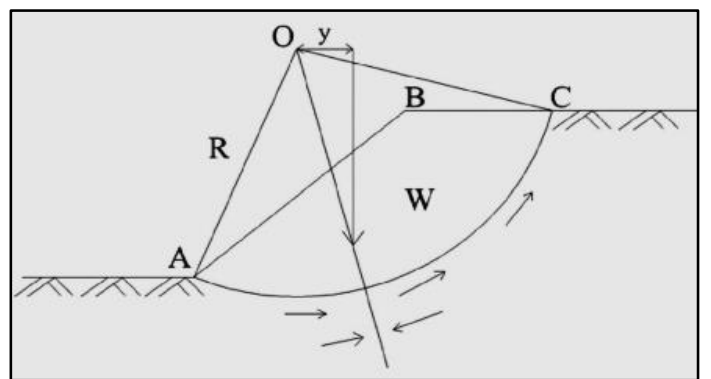

Gambar 2. Analisis stabilitas lereng tanah lempung tanpa rembesan 
Lereng yang dipengaruhi aliran air tanah, diperlukan gambar garis freatis dan sketsa jaring arus (flow-net). Garisgaris ekipotensial memotong bidang longsor dengan tinggi energy yang diketahui. Tekanan pada titik-titik dihitung dan digambarkan diagram tekanan air.

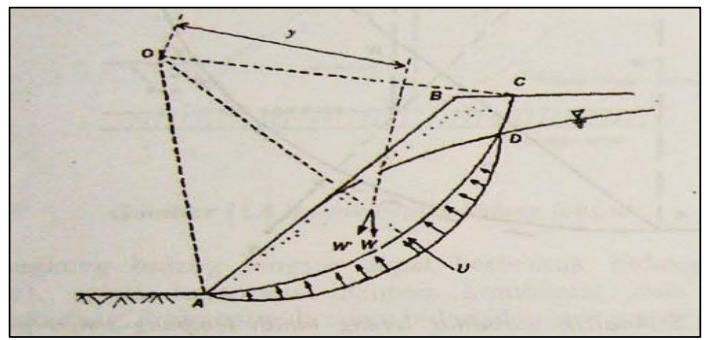

Gambar 3. Analisis Stabilitas Lereng

Tanah Lempung Dengan Rembesan

\section{Metode Irisan (Slice of Method)}

Dalam metode irisan, massa tanah yang longsor dipecah-pecah menjadi beberapa irisan vertikal. Kemudian, keseimbangan dari tiap-tiap irisan. Pada gambar dibawah ini memperlihatkan satu irisan dengan gaya-gaya yang bekerja padanya. Gaya-gaya yang terdiri dari gaya geser $\left(\mathrm{X}_{\mathrm{r}}, \mathrm{X}_{1}\right)$ dan gaya normal efektif $\left(E_{r}, E_{1}\right)$ di sepanjang sisi irisannya, dan juga resultan gaya geser efektif $\left(\mathrm{T}_{\mathrm{i}}\right)$ dan resultan gaya normal efektif $\left(\mathrm{N}_{\mathrm{i}}\right)$ yang bekerja di sepanjang dasar irisan.

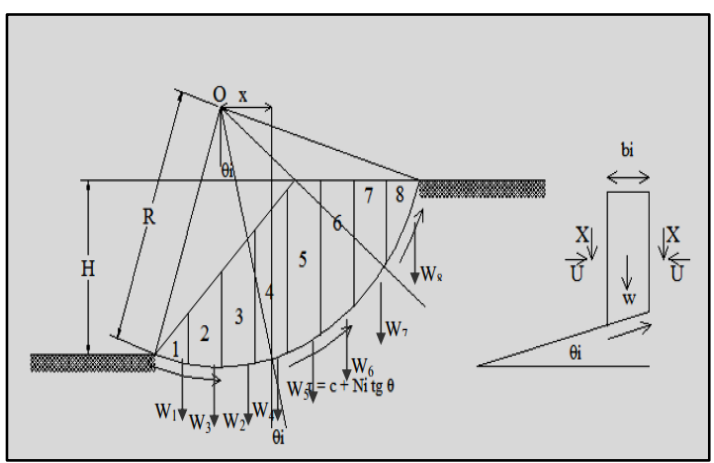

Gambar 4. Gaya-Gaya Yang Ada Pada Tiap Bidang Longsor

\section{Metode Fellenius}

Analisis stabilitas lereng cara Fallenius (1936) menganggap gaya gaya yang bekerja pada sisi kanan-kiri dari sembarang irisan mempunyai resultan nol pada arah tegak lurus bidang longsor. $\mathrm{E}_{1}=\mathrm{E}_{2}$ dan $\mathrm{V}_{1}=\mathrm{V}_{2}$

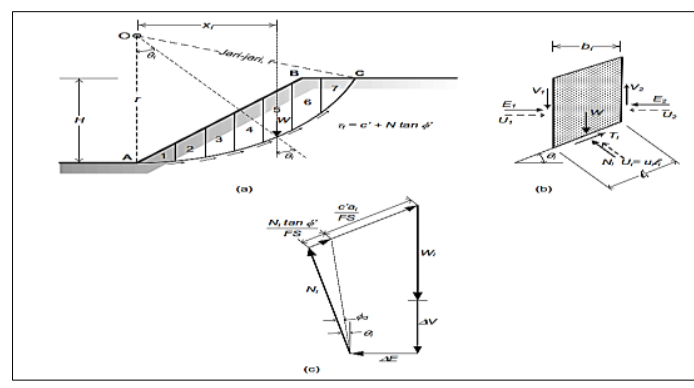

Gambar 5. Gaya - Gaya Yang Bekerja

Pada Irisan

Faktor keamanan didefinisikan sebagai;

$$
\begin{aligned}
& \mathrm{FK}=\frac{\sum \mathrm{M}_{\mathrm{r}}}{\sum \mathrm{M}_{\mathrm{d}}} \\
& \sum \mathrm{M}_{\mathrm{d}}=\mathrm{R} \sum_{\mathrm{i}=1}^{\mathrm{i}=\mathrm{n}} \mathrm{W}_{\mathrm{i}} \sin \theta_{\mathrm{i}}
\end{aligned}
$$

dimana:

$\mathrm{R}=$ Jari-Jari Lingkaran Bidang Longsor

$\mathrm{n}=$ Jumlah Irisan

$\mathrm{W}_{\mathrm{i}}=$ Berat Massa Tanah Irisan Ke- $\mathrm{i}$

$\theta_{\mathrm{i}}=$ Sudut Yang Didefinisikan Pada

Gambar di atas.

Dengan cara yang sama, momen yang menahan tanah yang akan lonsor, adalah :

$\sum \mathrm{M}_{\mathrm{r}}=\mathrm{R} \sum_{\mathrm{i}=1}^{\mathrm{i}=\mathrm{n}}\left(\mathrm{ca}_{\mathrm{i}}+\mathrm{w}_{\mathrm{i}} \cos \theta \tan \varphi\right)$.

Sehingga persamaan untuk faktor keamanan menjadi,

$\mathrm{FK}=\frac{\sum_{\mathrm{i}=1}^{\mathrm{i}=\mathrm{n}}(\mathrm{C} \cdot \Delta \mathrm{L}+\mathrm{Wi} \cos \theta \cdot \tan \varphi)}{\sum_{\mathrm{i}=1}^{\mathrm{i}=\mathrm{n}} \mathrm{W}_{\mathrm{i}} \sin \theta}$

Bila ada rembesan (ada pengaruh tegangan air pori) maka persamaan Fellenius menjadi :

$\mathrm{FK}=\frac{\sum_{\mathrm{i}=1}^{\mathrm{i}=\mathrm{n}}\left(\mathrm{C} \cdot \Delta \mathrm{L}+\left(\mathrm{Wi} \cos \theta-U_{n} \cdot \Delta \mathrm{L}\right) \cdot \tan \varphi\right)}{\sum_{\mathrm{i}=1}^{\mathrm{i}=\mathrm{n}} \mathrm{W}_{\mathrm{i}} \sin \theta}$

dimana:

FK= Faktor Keamanan

$\mathrm{C}=$ Kohesi Tanah $\left(\mathrm{kN} / \mathrm{m}^{2}\right)$

$\varphi=$ Sudut Geser Dalam Tanah (derajat) 
$\Delta \mathrm{L} \quad=\mathrm{b} / \cos \alpha(\mathrm{m})$

$$
\begin{gathered}
\mathrm{W}_{\mathrm{i}}=\text { Berat Irisan Tanah } \\
\mathrm{Ke}-i(\mathrm{kN})
\end{gathered}
$$

$\mathrm{U}_{\mathrm{n}}=$ Tekanan Air Pori Pada Pias Ke $-n$

\section{Debit Rembesan}

Debit rembesan (aliran) adalah kapasitas rembesan air yang mengalir ke hilir melalui tubuh dan pondasi tanggul. Debit rembesan suatu tanggul mempunyai batas-batas tertentu yang mana apabila debit rembesan melampaui batas tersebut, maka kehilangan air yang terjadi akan cukup besar. Disamping itu debit rembesan yang besar dapat menimbulkan gejala suforsi (piping) serta gejala sembulan (boiling) yang sangat membahayakan kestabilan tubuh tanggul (Sosrodarsono dan Takeda, 1977).

Hukum Darcy tepat untuk aliran rembesan di dalam tanah. Hukum ini mengansumsikan bahwa aliran air di dalam tanah merupakan aliaran laminier dan merupakan konsep dasar proses aliran air di dalam tanah dengan beberapa pengecualian. Asumsi lain adalah interaksi antara cairan dan tanah tidak menghasilkan perubahan dalam fluidityatau permeabilitydengan perubahanya gradient serta kondisi isothermal atau (isotropik) berlaku pada contoh tanah (Tampubolon, 1988).

Hukum Darcy dapat digunakan untuk menghitung debit rembesan yang melalui struktur bendung. Dalam merencanakan sebuah bendungan, perlu diperhatikan stabilitasnya terhadap bahaya longsoran, erosi lereng dan kehilangan air akibat rembesan yang melalaui tubuh bendung. Terdapat beberapa cara untuk menghitung debit rembesan yang melewati tanggul yang dibangun dari tanah urugan homogen diantaranya adalah :

\section{Cara A. Cassagrande}

Cassagrande (1973) dalam Hardiyatmo (2002) mengusulkan cara untuk menghitung rembesan lewat tubuh tanggul yang didasarkan pada pengujian model. Parabola AB (Gambar 2.4) berawal dari titik $A^{\prime}$ seperti yang diperlihatkan dalam Gambar 2.7 dengan $\mathrm{A}^{\prime} \mathrm{A}=0,3 \quad \mathrm{x}$ (AD). Menurut $\mathrm{A}$. Cassagrande debit rembesan dapat dihitung dengan menggunakan persamaan sebagai berikut:

$$
\begin{aligned}
& q=k a \sin ^{2} \dot{\alpha}, \text { dan } \\
& a=\sqrt{\left(d^{2}+H^{2}\right)}-\sqrt{d^{2}+H^{2} \operatorname{ctg}^{2} \alpha}
\end{aligned}
$$

dimana:

$$
\begin{aligned}
\mathrm{q} & =\text { Debit Rembesan }\left(\mathrm{m}^{2} / \mathrm{det}\right) \\
\mathrm{k} & =\text { Koefisien Permeabilitas (m/det) } \\
\alpha & =\text { Sudut Hilir Tanggul } \\
\mathrm{d} & =\text { Jarak Horisontal Antara E dan C } \\
(\mathrm{m}) & \\
\mathrm{a} & =\text { Panjang Zona Basah }(\mathrm{m}) \\
\mathrm{H} & =\text { Tinggi Muka Air }(\mathrm{m})
\end{aligned}
$$

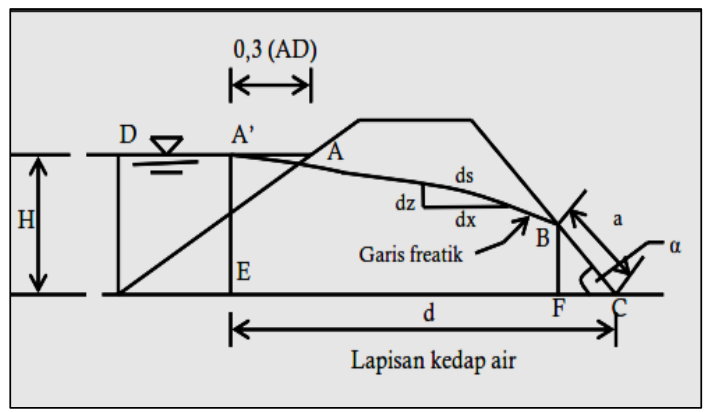

Gambar 6. Hitungan rembesan cara Casagrande

\section{METODE PENELITIAN}

\section{Waktu dan Tempat Penelitian}

Penelitian ini dilakukan dari bulan April sampai Oktober tahun berjalan sesuai jadwal kegiatan/program penelitian, di Lereng Daerah Aliran Sungai Way Batanghari tepatnya di titik lokasi penelitian ini yang berada di belakang Kampus 1 Universitas Muhammadiyah Metro.

\section{Data dan Informasi Penelitian}

Dalam penelitian ini diperlukan data-data untuk perhitungan baik data primer maupun data sekunder. Adapun 
data-data yang diperlukan dalam penelitian ini adalah :

\section{Data Primer}

Data primer adalah data utama, data yang diperoleh langsung oleh peneliti dari lokasi penelitian. Data-data tersebut diantaranya:

1. Kondisi penampang (melintang, memanjang, elevasi dan sudut kemiringan ekisting lereng tanggul sungai

2. Data pengujian tanah sebagai data kondisi lapisan tanah eksisting lereng tanggul

a. Nilai Kohesi tanah (c)

b. Nilai Berat volume $\operatorname{tanah}(\gamma)$

c. Nilai Sudut geser dalam $\operatorname{tanah}(\varphi)$

d. Nilai Koefisien permeabiltas tanah (k)

3. Data kondisi eksisting sungai dan aliran sungai, meliputi:

a. Lebar sungai

b. ketinggian muka air normal (MAN)

c. Ketinggian muka air banir (MAB)

d. Kecepatan aliran sungai

\section{Data Sekunder}

Data sekunder adalah data yang mendukung proses pembahasan yang diperoleh dari buku-buku refrensi, karya ilmiah yang berhubungan dengan penelitian dan instansi terkait untuk meminta data yang diperlukan seperti, Peta Daerah Aliran Sungai (DAS) dan data curah hujan harian yang diambil dari 2 (dua) stasiun pos hujan yang berpengaruh pada lokasi penelitan selama 10 tahun dari tahun 2009-2018.

\section{Peralatan Pengujian dan Bahan Penelitian}

Peralatan yang digunakan dalam penelitian ini adalah alat untuk pegujian-pengujian seperti tersebut di atas dan peralatan lainnya yang ada di Laboratorium Mekanika Tanah Jurusan Teknik Sipil, Universitas Muhammadiyah Metro. Adapun bahanbahan penelitian berupa sampel tanah yang diuji pada penelitian ini yaitu tanah yang berasal dari lereng di lokasi penelitian.

\section{Langkah Perhitungan dan Analisis}

Perencanaan stabilitas lereng/tanggul sungai diperlukan pemahaman tentang berbagai data yang saling terkait. Untuk itu di perlukan pengkajian secara detail sehingga setiap data yang digunakan akan sangat efektif dan efisien untuk digunakan sebagai masukan analisis lebih lanjut.

Beberapa langkah-langkah yang dapat dilakukan :

1. Langkah awal yaitu survei lokasi penelitian untuk mendapatkan datadata primer atau data utama mengenai kondisi lokasi penelitian.

2. Mengambil sampel tanah pada lokasi penelitian

3. Melakukan pengujian tanah untuk mendapatkan data tanah yang digunakan pada perhitungan stabilitas lereng/tanggul. Data yang dibutuhkan dalam pengujian tanah sebagai beriukut:

a. Nilai Kohesi tanah(c) $\left(\mathrm{kN} / \mathrm{m}^{2}\right)$

b. Nilai Sudut geser dalam $\operatorname{tanah}(\varphi)$ $\left({ }^{\circ}\right)$

c. Nilai Berat volume tanah $(\gamma)$ $\left(\mathrm{t} / \mathrm{m}^{3}\right)$

d. Nilai Koefisien Permeabiltas tanah $(\mathrm{K})\left(\mathrm{cm}^{2} / \mathrm{det}\right)$

4. Meminta data sekunder atau data pendukung pada intansi terkait dalam hal ini pada pihak Balai Besar Wilyah Sungai (BBWS) Kota Metro.

5. Setelah data-data tersebut didapatkan, nantinya menjadi sebuah paparan peneliti tentang apa yang diteliti dengan solusi yang akan diwujudkan oleh peneliti.

Peneliti merencanakan stabilitas dan perkuatan lereng yang didesain mampu menahan/mencegah penurunan tanah/longsoran pada lereng yang 
berasal dari pergerakan dan luapan air sungai way batanghari sehingga lereng mampu menahan pergerakan tanah pada lereng dan juga mencegah longsoran, gerusan yang terjadi pada lereng sungai tersebut.

\section{Analisis Hasil Penelitian}

1. Perhitungan Stabiltas Lereng/Tanggul Sungai, perhitungan stabilitas lereng dilakukan untuk medapatkan nilai faktor keamanan (FK) pada bidang longsor lereng/tanggul.

2. Menghitung Debit Rembesan pada Tubuh Lereng

3. Perhitungan parameter-parameter hidrologi meliputi, perhitungan curah hujan rencana, intensitas hujan, debit rencana dan kecepatan aliran sungai.

4. Perhitungan stabilitas dinding penahan tanah meliputi, menentukan jenis dan dimensi dinding penahan tanah, menentukan tapak dan pondasi, cek stabilitas dinding penahan tanah terhadap gaya geser, guling dan daya dukung tanah.

\section{HASIL PENELITIAN}

\section{Perhitungan Nilai Stabilitas Lereng}

Untuk menghitung stabilitas lereng tanggul diperlukan data dimensi lereng tanggul eksisting, rencana dan hasil pengujian tanah asli pada lereng tanggul, pengambilan sampel tanah dilakukan pada 3 (tiga) titik lokasi, yaitu titik 1 (satu) di bagian hulu lereng (batas tanah dengan Rusunawa Iringmulyo, di STA \pm 0.00 yaitu pada ketinggian 42,60 m DPL, titik 2 (dua) di bagian tengah bentang lereng, tepatnya di STA + 169.22 pada ketinggian 45,41 m DPL,sedangkan titik 3 (tiga) di bagian hilir lereng tanggul (mendekati batas tanah dengan MAN 1 Metro yaitu di STA + 188.26 pada ketinggian 41,27 m DPL. Lokasi Pengambilan sampel tanah dapat dilihat pada gambar di bawah ini.

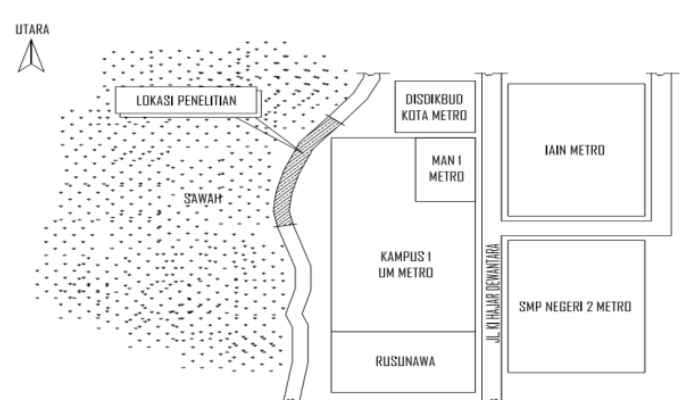

Gambar 7. Lereng/Tanggul lereng kampus 1 Universitas Muhammadiyah Metro

Kemudian sampel tanah yang didapatkan dari loksai penelitian dibawa ke Laboratorium mekanika tanah dan dilakukan pengujian untuk mendapatkan data tanah yang diperlukan dalam perhitungan stabilitas lereng tanggul dan debit rembesan tanggul.

\section{Pengujian Sampel Tanah}

Pengujian sampel tanah dilakukan di laboratorium Teknik Sipil Universitas Muhammadiyah Metro, pengujian yang dilakukan berupa pengujian tanah asli untuk mendapatkan nilai kadar air tanah, berat jenis tanah, berat volume tanah, batas cair, batas plastis, pemadatan, dan nilai kuat geser tanah langsung serta nilai permeabilitas untuk tanah asli berdasarkan standarisasi pengujian tanah.

Acuan Standarisasi Pengujian berupa : Pengujian Berat Jenis : SNI 1964 - 2008 Berat volume : SK SNI T-15-1990-03 Kuat Geser Tanah Langsung: SK SNI T15-1990-03

Pengujian Permeabilitas Tanah : SNI 03-1744-2012 
Tabel 2. Data Mekanika Tanah

\begin{tabular}{|c|c|c|c|c|}
\hline Parameter & $\begin{array}{c}\text { Titik 1 } \\
(\mathrm{P} .1)\end{array}$ & $\begin{array}{c}\text { Titik 2 } \\
(\mathrm{P} .2)\end{array}$ & $\begin{array}{c}\text { Titik 3 } \\
(\mathrm{P} .3)\end{array}$ & $\begin{array}{c}\text { Rata - } \\
\text { rata }\end{array}$ \\
\hline Kohesi (c) & $\begin{array}{c}0,18 \\
\mathrm{~kg} / \mathrm{cm} \\
2\end{array}$ & $\begin{array}{c}0,15 \\
\mathrm{~kg} / \mathrm{cm} \\
2\end{array}$ & $\begin{array}{c}0,17 \\
\mathrm{~kg} / \mathrm{cm} \\
2\end{array}$ & $\begin{array}{c}0,167 \\
\mathrm{~kg} / \mathrm{cm} \\
2\end{array}$ \\
\hline $\begin{array}{c}\text { Sudut Geser } \\
\text { Dalam }(\theta)\end{array}$ & $44,27^{0}$ & $37,70^{0}$ & $42,36^{0}$ & $41,44^{0}$ \\
\hline $\begin{array}{c}\text { Berat } \\
\text { Volume }(\gamma)\end{array}$ & $\begin{array}{c}4,3 \\
\mathrm{t} / \mathrm{m}^{3}\end{array}$ & $\begin{array}{c}3,46 \\
\mathrm{t} / \mathrm{m}^{3}\end{array}$ & $\begin{array}{c}3,01 \\
\mathrm{t}^{3} \mathrm{~m}^{3}\end{array}$ & $\begin{array}{c}3,59 \\
\mathrm{t} / \mathrm{m}^{3}\end{array}$ \\
\hline $\begin{array}{c}\text { Koefisien } \\
\text { Permeabilitas } \\
(\mathrm{K})\end{array}$ & $\begin{array}{c}3,623 \\
\mathrm{x} 10^{-4} \\
\mathrm{~cm} / \mathrm{s}^{2}\end{array}$ & $\begin{array}{c}3,623 \\
\mathrm{x} 10^{-4} \\
\mathrm{~cm} / \mathrm{s}^{2}\end{array}$ & $\begin{array}{c}3,623 \\
\mathrm{x} 10^{-4} \\
\mathrm{~cm} / \mathrm{s}^{2}\end{array}$ & $\begin{array}{c}3,623 \\
\mathrm{x} 10^{-4} \\
\mathrm{~cm} / \mathrm{s}^{2}\end{array}$ \\
\hline
\end{tabular}

(Laporan hasil Pengujian tanah di laboratorium, 2021)

Adapun nilai rata-rata Faktor Kemanan (FK) Lereng di masing-masing titik pada lokasi penelitian adalah sebagai berikut:
a. Titik I, nilai $\mathrm{FK}=2,5$
b. Titik II, nilai $\mathrm{FK}=2,4$
c. Titik III, nilai $\mathrm{FK}=3,2$

\section{Perhitungan Debit Rembesan Pada Lereng}

Perhitungan Debit Rembesan pada tubuh tanggul menggunakan cara Schaffernak. Menurut cara Schaffarnak menghitung debit rembesan menggunakan persamaan :

$\mathrm{q}=\mathrm{k} \cdot \mathrm{a} \sin \alpha \tan \alpha$

$a=\frac{d}{\cos \alpha}-\sqrt{\left(\frac{d^{2}}{\cos ^{2} \alpha}-\frac{H^{2}}{\sin ^{2} \alpha}\right)}$

dimana:

$\mathrm{q}=$ debit rembesan $\left(\mathrm{m}^{3} /\right.$ det $)$

$\mathrm{k}=$ koefisien permeabilitas $(\mathrm{m} / \mathrm{det})$

$\alpha=$ sudut hilir tanggul

$\mathrm{d}=$ jarak horisontal antara A dan B (m)

$\mathrm{a} \quad=$ panjang zona basah $(\mathrm{m})$

$\mathrm{H}=$ tinggi muka air $(\mathrm{m})$

Nilai Koefisien permeabilitas diperoleh dari nilai rata-rata pengujian permeabilitas tanah pada lokasi penelitian yaitu sebesar : $\mathrm{k}=3,623 \times 10^{-4} \mathrm{~cm} / \mathrm{s}^{2}$

$$
\begin{aligned}
\mathrm{a}= & \frac{\mathrm{d}}{\cos \alpha}-\sqrt{\left(\frac{\mathrm{d}^{2}}{\cos ^{2} \alpha}-\frac{\mathrm{H}^{2}}{\sin ^{2} \alpha}\right)} \\
& =\frac{7,70}{\cos 44}-\sqrt{\left(\frac{7,70^{2}}{\cos ^{2} 44}-\frac{1,5^{2}}{\sin ^{2} 44}\right)} \\
& =0,221 \mathrm{~m} \\
\mathrm{q} & =\mathrm{k} . \mathrm{a} \sin \alpha \tan \alpha \\
& =3,623 \times 10^{-4} \times 0,221 \times \sin 44 \times \tan 44 \\
& =0,534 \times 10^{-4} \mathrm{~m}^{3} / \text { det. } \\
& =5,34 \times 10^{-5} \mathrm{~m}^{3} / \text { det. }
\end{aligned}
$$

\section{Desain Gabion/Bronjong Untuk Perkuatan Tebing Sungai}

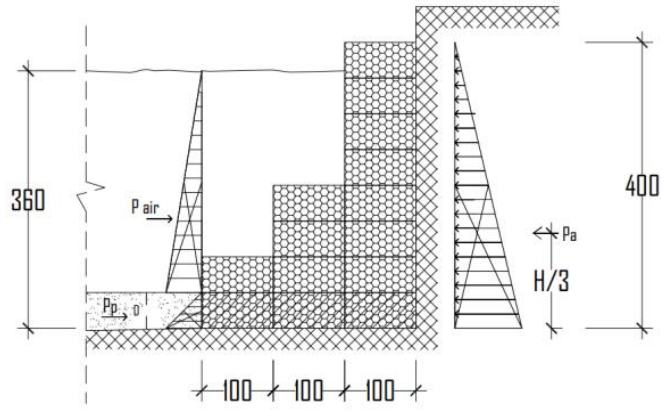

Gambar 8. Diagram Tekanan Tanah Aktif, Pasif Dan Air

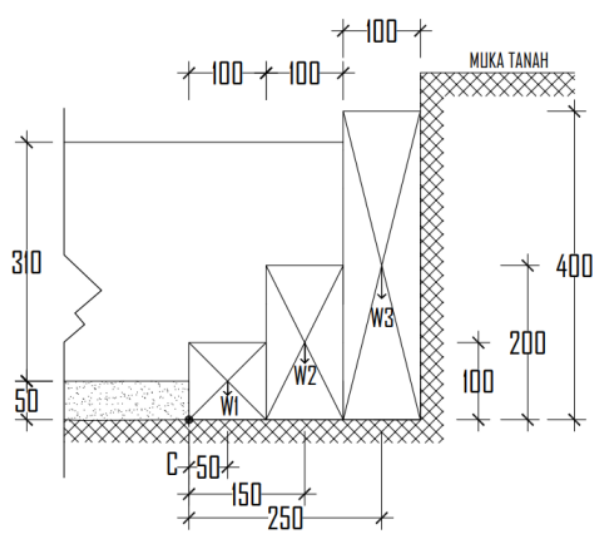

Gambar 9. Lengan Momen Pusat Area Terhadap Titik $\mathbf{C}$ 
Tabel 3. Perhitungan Berat Jenis Batu Gabion Bidang 1 - Bidang 3

\begin{tabular}{|c|c|}
\hline Bidang & Berat $(\mathrm{kN} / \mathrm{m})$ \\
\hline $\mathrm{w}_{1}$ & 25 \\
\hline $\mathrm{w}_{2}$ & 50 \\
\hline $\mathrm{w}_{3}$ & 100 \\
\hline Total & 175 \\
\hline
\end{tabular}

(Hasil Perhitungan, 2021)

\section{Perhitungan Jarak Beban Terhadap Ujung Dinding Penahan}

Tabel 4. Perhitungan Jarak Pembebanan Dari Bidang 1 - Bidang 3

\begin{tabular}{|c|c|}
\hline Bidang & Jarak $(\mathrm{m})$ \\
\hline 1 & 0,50 \\
\hline 2 & 1,5 \\
\hline 3 & 3 \\
\hline
\end{tabular}

(Hasil Perhitungan, 2021)

\section{Perhitungan Momen Terhadap Ujung Dinding Penahan}

Tabel 5. Berat dan Momen Tahanan

\begin{tabular}{|c|c|c|c|c|}
\hline Bidang & Luas & $\begin{array}{c}\text { Berat } \\
\text { per unit } \\
\text { panjang } \\
\mathrm{kn} / \mathrm{m}\end{array}$ & $\begin{array}{c}\text { Lengan } \\
\text { momen(m) }\end{array}$ & $\begin{array}{c}\text { Momen } \\
\text { terhadap } \\
\mathrm{C} \mathrm{kn} / \mathrm{m}\end{array}$ \\
\hline 1 & $\begin{array}{c}1 \mathrm{x} \\
1 \mathrm{x} \\
25\end{array}$ & 25 & 0,50 & 12,5 \\
\hline 2 & $\begin{array}{c}1 \mathrm{x} \\
2 \mathrm{x}\end{array}$ & 50 & 1,5 & 75 \\
& 25 & & & \\
\hline 3 & $\begin{array}{c}1 \mathrm{x} \\
4 \mathrm{x}\end{array}$ & 100 & 2,5 & 250 \\
& 25 & & & \\
\hline & & $\sum \mathrm{V}=$ & & $\sum \mathrm{M}_{\mathrm{R}}=$ \\
& & 175 & & 337,5 \\
\hline
\end{tabular}

(Hasil Perhitungan, 2021)

Tabel 6. Rekapitulasi Gaya dan Momen

\begin{tabular}{|c|c|c|c|}
\hline No & Nama gaya & kode & Gaya $(\mathrm{kN})$ \\
\hline 1 & $\begin{array}{c}\text { Tekanan } \\
\text { aktif }\end{array}$ & $\left(\sum \mathrm{M}_{\mathrm{pa}}\right)$ & 86,34 \\
\hline 2 & Pasif & $\left(\sum \mathrm{M}_{\mathrm{pp}}\right)$ & 14,45 \\
\hline 3 & Berat sendiri & $\left(\sum \mathrm{V}\right)$ & 175 \\
\hline \multicolumn{2}{|c|}{ Momen } & $\begin{array}{c}\text { Momen } \\
\mathrm{kN} / \mathrm{m}\end{array}$ \\
\hline 1 & Momen aktif & $\left(\sum \mathrm{M}_{\mathrm{O}}\right)$ & 94,04 \\
\hline 2 & $\begin{array}{c}\text { Momen } \\
\text { pasif }\end{array}$ & $\left(\sum \mathrm{M}_{\mathrm{p}}\right)$ & 14,45 \\
\hline 3 & $\begin{array}{c}\text { Momen } \\
\text { berat sendiri }\end{array}$ & $\left(\sum \mathrm{M}_{\mathrm{R}}\right)$ & 337,5 \\
\hline
\end{tabular}

(Hasil Perhitungan, 2021)
Perhitungan Stabilitas Terhadap Guling (Overturning)

Bangunan dinding penahan tanah dikatakan aman apabila angka keamanan lebih dari 1,5 dan dikatakan bergeser apabila angka keamanan kurang dari 1,5 (factor aman yang disyaratkan ).

$$
\begin{aligned}
\mathrm{FS}_{(\text {guling })} & =\frac{M_{R}}{M_{O}}>1,5(\text { tanah granular }) \\
& =\frac{337,5}{94,04}=3,59>1,5 \quad(\mathbf{O K})
\end{aligned}
$$

Berdasarkan perhitungan tersebut, dinding penahan tanah/dinding Gabion ini aman dari guling, karena $\mathrm{FS}_{(\text {guling })}>$ 1,5 .

\section{PerhitunganStabilitas Terhadap Geser (sliding)}

Faktor keamanan terhadap stabilitas geser :

$\mathrm{FS}_{(\text {geser })}=\frac{(\Sigma V) \tan (\mathrm{k} 1 \emptyset 2)+B K 2 c_{2}+P_{p}}{P_{a}}$

Untuk $\mathrm{k} 1=\mathrm{k} 2=2 / 3$ dan asumsi $\mathrm{P}_{\mathrm{P}}=0$

$$
\begin{aligned}
\mathrm{K}_{\mathrm{P}} & =\tan ^{2}\left(45+\frac{\emptyset}{2}\right) \\
& =\tan ^{2}\left(45+\frac{41,44}{2}\right)=2,22 \\
\mathrm{D} & =0,5
\end{aligned}
$$

Maka :

$$
\begin{aligned}
\mathrm{FS}_{(\text {geser })}= & \frac{(\Sigma V) \tan (\mathrm{k} 1 \emptyset 2)+B K 2 c_{2}+P_{p}}{P_{a}} \\
& =\frac{(175) \tan \left[\frac{2}{3}(41,44)\right]+(3) \frac{2}{3} 16,66+0}{64,62} \\
& =\frac{91+32+0}{63,34,62}=1,92>1,5 \quad \text { (OKE) }
\end{aligned}
$$

\section{Perhitungan Stabilitas Terhadap Daya Dukung}

Untuk menguji faktor keaman terhadap keruntuhan daya dukung dapat ditahan oleh tanah dasar, maka dihitung

$$
\begin{aligned}
& \mathrm{e}=\frac{B}{2} \frac{\sum \mathrm{M} R-\sum \mathrm{Mo}}{\sum \mathrm{V}} \\
& \mathrm{e}=\frac{3}{2}-\frac{337,5-94,04}{175} \\
& =0,11<\frac{B}{2}=\frac{3}{2}=1,5
\end{aligned}
$$




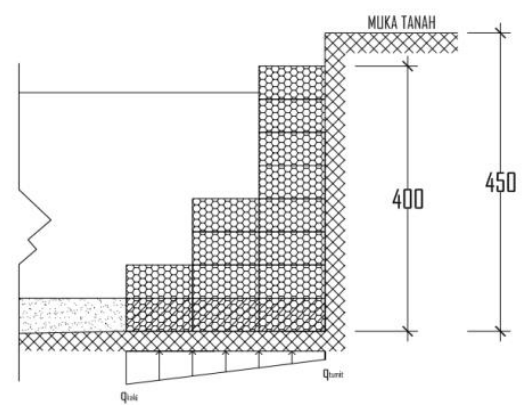

Gambar 10. Diagram Tegangan Maksimum Dan Minimum

Tabel 7. Hasil Perhitungan Faktor Keamanan

\begin{tabular}{|c|c|c|}
\hline $\begin{array}{c}\text { Faktor } \\
\text { keamanan }\end{array}$ & $\begin{array}{c}\text { Hasil } \\
\text { perhitungan }\end{array}$ & Kondisi \\
\hline $\begin{array}{c}\mathrm{FS}_{\text {(guling) }}> \\
1,5\end{array}$ & 3,59 & Stabil \\
\hline $\begin{array}{c}\mathrm{FS}_{\text {(geser) }}> \\
1,5\end{array}$ & 1,92 & Stabil \\
\hline $\begin{array}{c}\mathrm{FS}_{\text {(daya }} \\
\text { dukung) }>3\end{array}$ & 3,48 & Stabil \\
\hline
\end{tabular}

(Hasil Perhitungan, 2021)

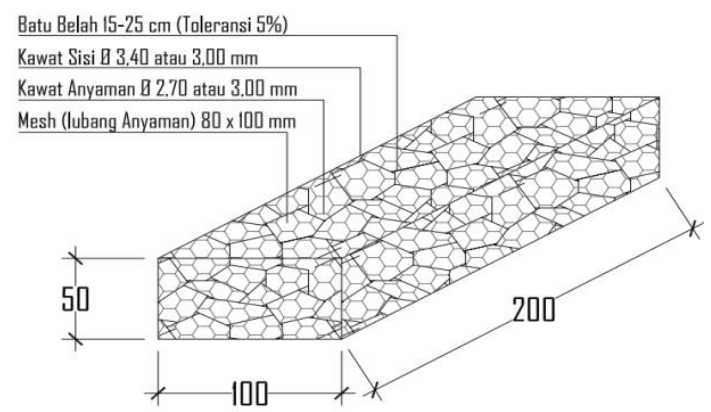

Gambar 11. Dimensi Gabion/bronjong

Sehingga dapat di peroleh volume dalam 1 keranjang kawat gabion :

$$
\text { Luas : } \begin{aligned}
\mathrm{V} & =\mathrm{p} \times 1 \times \mathrm{t} \\
& =2 \times 1 \times 0,5 \\
& =1 \mathrm{~m}^{3}
\end{aligned}
$$

Dengan diameter batu $15 \mathrm{~cm}-25$ cm (toleransi 5\%) dan sekurang kurang nya $85 \%$ dari batuan yang digunakan harus mempunyai ukuran yang sama atau lebih besar dari ukuran dari ukuran tersebut serta tidak boleh ada batuan yang diizinkan melewati lubang anyaman.Dengan berat isi batu 25,000 $\mathrm{kN} / \mathrm{m}^{3}$.

\section{KESIMPULAN}

Dari hasil analisis stabilitas lereng tanggul dengan metode irisan (method of slice) dengan cara fellenius, didapatkan faktor keamanan (FK) rata-rata terbesar yaitu 3,235>1,5, dalam hal ini lereng tersebut dalam keadaan stabil atau aman dari bahaya longsoran. Berdasarkan perhitungan debit rembesan didapatkan debit rembesan pada tubuh lereng sebesar $=5,34 \times 10^{-5} \mathrm{~m}^{3} / \mathrm{det}$, rembesan air yang yang terjadi pada tubuh lereng pada saat banjir dapat mempengaruhi penurunan kestabilan lereng, dimana rembesan tersebut akan menyebabkan gejala piping (proses terangkutnya butir-butir tanah halus yang menyebabkan aliran air dalam tubuh lereng).

Dari Perhitungan Stabilitas Struktur Kontruksi Dinding Penahan lereng dengan menggunkan Gabion/Bronjong. Data tersebut dapat disimpulkan faktor keamanan (FK) dinyatakan stabil. Dan faktor keamanan nya adalah FS (guling) $3,59(>1,5), F S$ (geser) $1,92>(1,5)$,FS (daya dukung) 3,48(> 3).Itu berarti berdasarkan hasil penelitian di atas, menunjukan bahwalereng sepanjang Kampus 1 Universitas Muhammadiyah Metro sepanjang 120mdengan perencanaan struktur dinding penahan tanah dengan menggunkan Gabion/Bronjongdapat dinyatakan stabil.

\section{DAFTAR PUSTAKA}

Anonim. AASTM D-4318, AASTM D422, AASTM D-854, AASTM D698-78, AASTM D 4429-04.

Anonim, 2003. Pengaman Sungai; Balai Sungai, Departemen Pemukiman dan Prasarana Wilayah, Bandung.

Asdak, Chay, 2002. Hidrologi dan Pengelolaan Daerah Aliran 
Sungai. Gajah Mada University Press, Yogyakarta.

Balai Besar Wilyah Sungai (BBWS) Mesuji Sekampung.

Bowles, Joseph E. 2010. Sifat-sifat Fisis dan Geoteknis Tanah (Mekanika Tanah), Erlangga, Jakarta.

Das B.M. 1994. Mekanika Tanah 1 Prisip Rekayasa Geoteknis Jilid 1. Erlangga. Jakarta

Direktorat Jendral Bina Marga. 2018. Spesifikasi Umum 2018 Untuk Pekerjaan Konstruksi Jalan dan Jembatan.

Hardiyatmo, H. C., 2012. Mekanika Tanah I, Edisi ke enam ,Gajah Mada University Press, Yogyakarta.

Hardiyatmo, H. C., 2010 . Mekanika Tanah II, Edisi ke lima, Gajah Mada University Press, Yogyakarta.

Hardiyatmo, Christady Hary, 2014. Analisis dan Perencanaan Fondasi I, Gajah Mada University Press, Yogyakarta.

Karmiana, I Made, 2011. Teknik perhitungan Debit Rencana Bangunan Air, Graha Ilmu, Palangkaraya.

Laporan Praktikum, Mekanika Tanah I, Universitas Muhammadiyah Metro.

Muntohar A. S., Tanah Longsor, Universitas Muhammadiyah Yogyakarta.

Peraturan Menteri Pekerjaan Umum dan Perumahan Rakyat Republik Indonesia No. 28/PRT/M/2015, tentang Penetapan Garis Sempadan Sungai dan Garis Sempadan Danau. Menteri Pekerjaan Umum dan Perumahan Rakyat, 2015.

Soedarmono. D., Purnomo. E., 1993. Mekanika Tanah I, Kanisius, Malang.

SNI, 2415 : 2016,Tata Cara Perhitungan Debit Banjir Rencana, Jakarta, (BSN) Badan Standar Nasional. 